\title{
(息)
}

Citation:

Dulaimi, $M$ and Hariz, A (2011) The impact of Cultural Diversity on Construction Project Team Performance. Engineering project Organisation. ISSN 2157-3727 DOI: https://doi.org/10.1080/21573727.2011.621419

Link to Leeds Beckett Repository record:

https://eprints.leedsbeckett.ac.uk/id/eprint/4695/

Document Version:

Article (Accepted Version)

The aim of the Leeds Beckett Repository is to provide open access to our research, as required by funder policies and permitted by publishers and copyright law.

The Leeds Beckett repository holds a wide range of publications, each of which has been checked for copyright and the relevant embargo period has been applied by the Research Services team.

We operate on a standard take-down policy. If you are the author or publisher of an output and you would like it removed from the repository, please contact us and we will investigate on a case-by-case basis.

Each thesis in the repository has been cleared where necessary by the author for third party copyright. If you would like a thesis to be removed from the repository or believe there is an issue with copyright, please contact us on openaccess@leedsbeckett.ac.uk and we will investigate on a case-by-case basis. 


\section{The Impact of Cultural Diversity on the Effectiveness of Construction Project Teams}

To cite this article: Mohammed Dulaimi \& Amjad Hariz (2011) The impact of cultural diversity on the effectiveness of construction project teams, Engineering Project Organization Journal, 1:4, 213-221, DOI: 10.1080/21573727.2011.621419

\section{Abstract}

Before the Global Financial Crisis hit the region in 2008 the buoyant construction activities in the United Arab Emirates, and especially in Dubai, was successful in attracting many multinational companies and professionals from across the globe. One of the main drawbacks of this business environment is the increasingly high competition between such companies to recruit and retain the needed human resources. This paper has investigated the cultural diversity phenomenon in construction project teamss in Dubai and its affect on their effectiveness. The main objective of the paper is to examine the impact of cultural diversity of the project team on their performance. The paper reports the results of an empirical study into the relationship between the extent of cultural diversity and project team performance. The findings of the empirical study suggest that there is no significant relationship between the degree of project team cultural diversity and their overall performance measure. However, the results showed that there is a negative relationship between the degree of cultural diversity and output, productivity, and efficiency.

Keywords: Project Team, Cultural diversity, team performance, Leadership.

\section{INTRODUCTION}

The United Arab Emirates (UAE) has become the destination for many multinational companies attracted by the massive development programme especially that in construction. The construction industry in the UAE has been expanding progressively over the last two 
decades. Before the global financial of 2007 reached the region the speed of expansion of the industry was accelerating exponentially with almost every week there is an announcement of a new major development. This rapid expansion has stretched the construction industry resources beyond its capacity. The capacity problem in the UAE was compounded by the fact that such a boom coincided with similar booms in neighbouring Bahrain and Qatar and the massive developments in the Kingdom of Saudi Arabia. It is not surprising that the UAE, and especially major clients, was keen to attract international construction firms and professionals to relocate to the county to fill vacant positions and avoid a possible stalling of the UAE ambitious development programmes. Dubai Chamber of Commerce and Industry (DCCI) Economic Bulletin in June 2007 showed that GDP for the UAE grew to AED 599,231 million (1US\$=3.67 AED) in 2006 from 485,521 million in 2005. The average UAE GDP growth over 2001-2006 was 8.4\% compared with $6.5 \%$ average for the whole Gulf Cooperation Council (GCC) (OBG 2007a). The DCCI statistics also showed that the construction industry of the UAE contribution to GDP grew from AED 34,980 million in 2005 to AED 45,124 million in 2006. GDP grew by $9.2 \%$ in 2006 compared to $16.8 \%$ in 2005 (OBG 2007b). GDP is expected to grow from US\$29.65bn in 2005 to US\$44000 in 2015 (OBG 2007b).

One of the main priorities of the country is to increase the number of nationals working in the private sector. However, the workforce in the UAE is still dominated by expatriates, representing over $90 \%$ of the workforce in the private sector. This means the "host" culture is almost certainly be a minority in a project environment. Figures from ADCCI (2007) show the size of the workforce in the UAE to have reached 2.82 million people in 2007 . The ADCCI construction industry figures, including the suppliers and repair activities as well as 
the real estate sector, shows the industry grew from just over 1 million workers in 2005 to over 1.2 million in 2007, an increase of $11 \%$ over 2 years.

Dubai, one of the seven Emirates making up the UAE, has grown rapidly to expand its construction development activity even beyond the traditional bases in the region. Over the last five years developers, contractors and consultants, such as EMAAR and Arabtec, branched out across the Middle East and further into Asia and Africa. This rabid expansion of the industry in a country that is sparsely populated has lead to a global hunt for human resources. Construction firms have recruited staff from across the world and across all levels, senior management to casual labourer. In such a business environment cultural diversity management should be a priority for management. Anecdotal evidence, however, shows that many business organisations in the UAE are struggling to effectively manage and harness such cultural differences with communication lapses, fragmented teams and increased levels of conflict impacting significantly the ability of multicultural teams and organisations to deliver satisfactory products and services to customers. Therefore, the research has set its objective to examine the influence of cultural diversity in construction projects on project team effectiveness.

\section{MANAGEMENT OF CULTURALLY DIVERSIFIED PROJECT TEAMS}

Multiculturalism brings new challenges to project execution in globalised markets. In such a context culturally diverse teams are expected/ required to work in an integrated manner while struggling to overcome differences stemming from their diverse cultures. 
Researchers have identified several primary dimensions to diversity such as ethnicity, nationality, learning style, types of intelligence, age, gender, and physical abilities (Vecchio and Appelbaum, 1995; Francesco and Gold, 2005). Francesco and Gold (2005, p. 194) argued that it is through these dimensions people tend to shape their self-image and world view. Daft (2003) differentiates diversity at two different dimensions, basic dimension and secondary dimension. Basic dimensions are race, ethnicity, gender, physical or cognitive capability, which depict differences which are inborn or have influence on individuals during their life span; these are also the core elements shaping perspectives or self-images of individuals. Secondary dimensions are the characteristics which individuals have possessed throughout their lives; in other words, the qualities acquired later on and, hence, usually changeable.

The concept of culture diversity has been defined in different ways to reflect the different perspectives and interests of researchers. In this research we have used cultural diversity to refer to the existence, within a particular context, of individuals with differing national cultures. Cox (1993) stated that cultural diversity exists when people with distinct group affiliations of cultural significance are found within a larger group or organisation. Members of a cultural identity group tend to share certain norms, values, priorities and socio cultural heritage. Teams can be homogenous where team members come from the same cultural group, or multicultural, where team members come from more than one culture. Adler and Gunderson (2008) went further and referred to teams whose all members come from the same cultural background except one member as token teams, bicultural teams where there are two distinct cultures in the team, and multicultural teams are teams with three or more cultures. The situation in construction projects in the UAE is expected to be of last type. 
As to the impact cultural diversity can have on teams' performance the expectation is that such teams can perform better than more than homogenous teams, but with the risk of experiencing greater losses due increased conflict in agreeing on working practices and processes (Adler and Gunderson, 2008). Diversity, hence, appears to be a double-edged sword. While diversity is seen to increase the opportunity for creativity but at the same time increases the likelihood of dissatisfaction and failure to identify with one's workgroup (Milliken and Martin, 1996). Research has also shown that diverse teams suffer more from poor cohesion and social integration than more homogeneous teams (Hambrick, 1994), conflict, turnover, low trust, low job satisfaction, stress, absenteeism, and communication difficulties (Adler and Gunderson, 2008). Dulaimi (2008) argued that such diverse teams have the opportunity to create new solutions. Watson et al. (1993) suggested that well-led diverse teams can outperform homogenous teams by as much as 15 percent. Williams and O'Reilly (1998) reviewed the literature in this field and conclude that heterogeneity generally leads to low satisfaction, low commitment, and low social integration. The same study showed that heterogeneity in functional background and race/ethnicity may improve group performance through the contribution of diverse information and skills. McCuiston et al. (2004) argued that diversity can improve companies' bottom line by improving corporate culture, improving relationships with clients, retaining talented employees, decreasing complaints, and improving employee morale. Although the creation of cultural "enclaves" within organisations can provide the space where cultural, minority, groups find social support and networking it is seen to weaken links and cohesion with other cultural groups (Loosemore et al. 2010). Seymen (2006) review of the relevant literature led him to conclude that cultural diversity is an important tool for competitive superiority for organisations and 
therefore they should be supported. He stated also that the increase of cultural diversity necessitates managers to possess the information and understanding about how to manage people who are very different from each other in order to reach common goals. Managers working with a workforce that has cultural diversity have to use variable management and organisational behaviour techniques which harmonise different workforce needs and values (Wright and Noe, 1996). Miller and Rowney (1999) research on the management of diversity in the workplace pointed out the importance of management of diverse workforce through human resource training programs.

Cultural diversity management can be seen as the answer or reaction of organisations aiming to enhance their performance and competitiveness but at the same time have to deal with increased diversity of its workforce (Fleury, 1999). However, such teams are more likely to face difficulties such as miscommunication, low performance, lack of transparency, ineffective team development, lack of cultural awareness, and poor management of conflict (Adler, 1991; Shenkar and Zeira, 1992; Iles, 1995; Proehl, 1996; Matveev and Milter, 2004). Such conflicts may be task related or relationship related (Chuang et al. 2004). Task-related conflict refers to disagreements among group members about task issues, including the nature and importance of task goals, key decision areas and procedures. Relationship conflict refers to interpersonal incompatibilities among group members, including tension, animosity and annoyance (Jehn, 1995). Appelbaum et al. (1998) examined the relation between groups' diversity and conflict and concluded that group process and conflict are affected by cultural lenses. They explained how mistrust and miscommunication are the main sources of conflict in such teams. Trust in a multi-cultural task group is difficult to develop when research has 
shown that group members tend to rally around their own nationals (Triandis et al., 1965, 33$35)$.

Cultural diversity has an important place in the communicational problems in multinational or global business (Seymen, 2006). Karoc-Kakabadse and Kouzmin (2001) argued that the major reasons for difficulties encountered in cross-cultural communication stem from the fact that actors from different cultures have different understanding regarding the interaction process and different styles of dialogue. Communication involves the exchange of meaning and includes any behaviour another person perceives and interprets (Adler, 2002). Researchers have identified several reasons for communication failure across cultures (Luthans, 2005; Adler, 2002) all of which seem to focus on the failure of individuals to effectively encode and decode messages across the cultural divide. Adler (2002) argues that the greater the difference between the sender's and the receiver's culture, the greater is the chance for cross-cultural miscommunication. Similarly, attempts to evaluate an individual from a different culture are undermined when the evaluators use their own culture as "standard of measurement, judging things, so our culture becomes a self-reference criterion."

Cox (1991) argued that the effective management of diversity can help organisations generate benefits to the organisation in areas such as cost, resource acquisition, marketing, creativity, problem solving, and flexibility. The need to adopt different management approaches has prompted researches to argue that some managers may be successful in mono-cultural contexts but not in multicultural one (Gregersen et al. 1998; Jokinen 2005). In a multicultural environment managers need to recognise and demonstrate respect to the differing values and attitudes of the different cultural groups in their organisations, avoid stereotyping, provide a 
psychologically safe environment for people to air their views, and avoid projecting or imposing their own culture and value system onto others (Abbassi and Hollman 1991).

Review of the literature on research that tried to link cultural diversity and team performance revealed mixed results. Richard et al. (2007) research, based on Blau's (1977) theory of heterogeneity with knowledge-based view, provided evidence of the curvilinear relationship between racial diversity and intermediate performance. They discovered a stronger effect of racial diversity would be found for service-oriented firms. However, Kokt (2003) research of major security companies in South-Africa found no significant effect of cultural diversity on the team performance.

In construction research, Fellows and Liu (2006) argued that the criteria for evaluating performance, including the project's, are generated by the values of major participants and therefore it is important that those criteria "be determined rigorously, early, and with cultural sensitivity as an accepted amalgam of requirements of all participants in the JV to foster goal congruence and, then, maintained intact as the basis for subsequent evaluations". However, Mahalingam and Levitt (2007) have criticised researchers into cultural diversity for not focusing enough on construction project teams as the unit of analysis. They explain that due to the temporary nature of projects processes such as learning, resolution of conflict, ..etc, do not have sufficient time to "develop fully". Further, they argued that such research tends to adopt a monolithic view of culture and not distinguish how different professional orientation may play a role in influencing the dynamics in a multicultural team. However, Hofstede (1980) research led him to conclude that national culture explains more of work related attitudes and values than their profession. 
The research reported in this paper focuses on national culture to examine the impact of diversity on performance of construction project teams in the UAE. National culture is used to refer to deeply set values that are common to the members of any one particular nation. Hill (1997, p67) describe national culture as a system of shared norms, values, and priorities that, taken together, constitute a 'design for living' for a people. Hofstede $(1980,1997)$ and Hampden-Turner and Trompenaars (1993) developed and proposed two different sets dimensions that can explain differing values and attitudes which would influence behaviour and interaction with members of different national cultures. Hofstede research (1997) found that national culture explains $50 \%$ of the differences in managers' attitudes, beliefs and values. Similarly Managers of multinational organisations are seen to retain many of their original national values despite routinely working in culturally diverse situations (Sermon and Lane, 2004; Seymen, 2006). However, there are views to the contrary. Adler and Gunderson (2008) explains that many managers believe that organisational culture moderates or erases the influence of national culture, and employees working in the same organisation even, if they come from different countries, will behave more similarly than differently. Shankar (2001) dealt with the concept of cultural distance to add to the debate the extent to which national cultures are different explain how such phenomena can impact multicultural teams. Miroshnik (2002) referred to the "cultural blindness" of managers who do not want to see cultural differences between nationalities and hence limits the ability of management to manage cultural diversity effectively. Further Laurent (1983) research found that employees working for a multinational company have shown stronger cultural differences than their colleagues who worked at the same company in their homeland. Seymen (2006) 
explained that in industrialised countries there are fewer cultural differences or value-oriented work in organisations, and it is much easier to manage cultural diversity.

The context of the UAE is significantly different from the context of what has been described above. Anecdotal evidence shows that dozens of different nationalities are present in many business organisations in the country. In addition, the UAE provides a unique challenge since the "host" culture, i.e. of the nationals of the UAE, is not represented in any significant way in the private sector, especially in the construction industry. The absence of a host culture may motivate different national groups to show stronger cultural differences and push for dominance by imposing their own culture and value system on others increasing fragmentation and conflict.

\section{THE RESEARCH}

The focus of this research is on understanding the impact of cultural diversity in construction project teams on their performance. The research has collected data, from current projects in Dubai, which described the extent of diversification, project management style, and project team performance. The analysis of the data should allow the research to examine the relationship between the extent of cultural diversity and project team performance.

The field work has also collected data that would enable the evaluation of project management style adopted on site to gauge any significant differences in relation to cultural diversity. The main data collection was through a survey targeting construction project 
managers. The analysis of the data collected from the survey is complemented by a number of interviews with project managers to shed more light on the issue of cultural diversity and its affect on project teams and project performance in the context of the UAE.

The research approached one of the largest contractors in Dubai to take part in the study and allow a sample of project managers to be selected from those managing their existing pool of projects. Although the use of one company maybe seen to limit the generalisation of the results it should be emphasised that the focus is on projects and project teams and hence can be argued that the unit of analysis is typical of projects in Dubai/UAE. This particular contractor was approached because one of the authors is an employee and would be able to facilitate data collection. All projects were residential projects to build villas in a number of locations in Dubai. Thirty one project managers expressed willingness to participate in the survey and all returned their completed questionnaires. The decision to limit the sample to one contractor is taken to eliminate the influence of differing organisational environment, processes and practices. More importantly such decision would control the effect of organisational culture which was argued earlier, (Adler and Gunderson, 2008), to moderate the effect of multiculturism. This would give the research greater confidence in analysing the relationships between the main variables, the extent of cultural diversity in the project team, project team performance and project management style.

The survey consisted of two main parts. Part 1 of the questionnaire requires project managers to evaluate their project team performance on a number of criteria (table 1). The research decided not to collect data on project performance as this factor can be influenced by many other factors beyond the control of the project manager and the team. It was important to 
measure team performance using different criteria to be able to capture the likely differing influences of cultural diversity. In examining the body of knowledge on team performance two issues were identified performance behavior and outcomes. In their review of 10 year of Mathieu et al (2008) explained that in measuring team performance there is what is referred to as performance behaviors which are behaviors that are relevant to achieving the objectives such as effective communication, supporting other team members. There is also the outcome which is related to, for example, the quality, cost, timely delivery of objectives. Therefore, there is a need to use a multi-criteria measure for project team performance to be able to gauge the impact of cultural diversity on project team performance.

The research identified a measure used by the targeted contractor to enable project managers evaluate, bi-annually, the performance of project teams. Table 1 shows the adopted appraisal system with a clarification of each criterion used in measuring team performance. The use of a measure that is already being used by the target population gave advantage to the research that the project managers are already familiar with the tool and will be able to respond without a risk of misinterpretation and limiting subjectivity due their experience in using the measure and being accountable for their assessment. Each criterion of the appraisal has a different weight/scale based on its perceived importance to the company, and this is given in the number of points that each criterion scores. The total score for the appraisal represents the overall team performance out of 60 points which can be turned into percentage.

Part 2 of the questionnaire measures the management style of project managers using the Least Preferred Co-worker (LPC). LPC measure has been used to evaluate the extent which the project manager is more task oriented or relationship oriented in their management of 
their team (Robbins, 2005). This tool has shown to distinguish between the different construction project managers' approaches (Dulaimi and Langford 1999) and should allow the research to examine the impact of project management style on multicultural teams' performance. It is expected that project managers will be adopting a more employee oriented approaches in a more culturally diverse teams in order to manage diversity.

*** Insert here table $1 * * * * *$

The questionnaire also collected data to measure the extent of cultural diversity using Blau's Index of diversity (1977). Blau's Diversity Index $=\left(1-\sum \mathrm{Pi}^{2}\right)$, where $\mathrm{Pi}$ is the proportion of group members in category i. category will be the nationality of team members in this research (Richard et al., 2007). The index ranges from 0 to 0.8 . As the cultural diversity degree of the team members increases, as the diversity index increases in its value, 0 index means one-culture project team members, which is the lowest degree of diversity can be, 0.8 diversity index means the highest degree of cultural diversity within a project team, it means actually that all team members are distributed equally on each cultural category. In addition, the research collected data on project team size, project duration and value.

\section{DATA ANALYSIS AND DISCUSSION}

Team performance, diversity index, and LPC score measures were calculated for each questionnaire. The scores given for each performance parameter in each questionnaire were turned to percentages by dividing each score result on the weight of that performance parameter (see table 1). 
Figure 1 shows that the majority of the projects in the sample had a high diversity index, more than 0.5 , which was expected considering the high level of cultural diversity of the population of the country. Figure 1 also shows the relationship between the cultural diversity given by Blau's Diversity Index and the project team performance. This relationship is linearly negative, which means that as the diversity index increases the team performance decreases; in other words, the national diversity of a project team has a negative impact on the whole project team performance. The correlation coefficient of this relationship is $\mathrm{r}=-$ $0.285\left(\mathrm{R}^{2}=0.0815\right)$. In the multiple regression analysis the coefficient of correlation for $X_{1}$ variable (cultural diversity) is $\beta_{1=-0.46}$ and $P$-Value $=0.217(P>0.05)$, which means that the correlation between the overall project team performance and team national diversity is not significant at $95 \%$ confidence level. This reveals a negative correlation between the cultural diversity and the project team performance but not significant for the sample studied in this research.

One of the reasons behind the insignificance of the correlation between cultural diversity and team performance may be related to two possible factors. The first is the small sample size that has been studied; only 31 questionnaires. Another reason may be the fact that the research did not take into account other important factors that may affect this correlation, for example the time a diverse project team have spent working together. Richard et al., (2007) explained that long-term diverse teams perform better than short-term diverse teams. Their research shows that the relationship between the project team diversity and its performance takes a curvilinear shape over time, so it starts improving over time after getting over the diversity 
problems that occur at the starting of the project team. This important time or termrelationship was not considered in the analysis which may have affected the results.

$* * * *$ Inset figure 1 here $* * * * *$

The results have shown the sample having an LPC average of 4.33 indicating the project managers in this sample are on average employee oriented (Fiedler and Garcia, 1987). This is in line with what the research has indicated earlier of the need for project managers to adopt such approach. The relationship between the diversity index of a project team and the project management/ leadership orientation is very weak with the correlation coefficient at $\mathrm{r}=0.063$ $\left(\mathrm{R}^{2}=0.004\right)$. This means that there is no significance relationship between the team diversity and project management style. Similarly the LPC relationship with the team performance is found to be not significant at $95 \%$ confidence level, $\beta_{2}=0.020$ and $P$-Value $=0.483>0.05$.

The analysis of the different performance criteria have shown that correlation with cultural diversity is not significant at $\mathrm{P}<0.05$ except for one performance criterion which is output, productivity, and efficiency $(O P E)$. The correlation between OPE and the extent of cultural diversity of a project team is significant having $\mathrm{P}$-value $=0.026<0.05$. Figure 2 shows that output seems to suffer as the diversity index increases. This shows that on the two elements that the literature has emphasised, i.e. performance behaviour and outcome, it is the outcome that has suffered in a diversified team. It may be argued that while the team was able to demonstrate the necessary performance behaviours they were unable to translate such behaviour into positive outcomes. It could be that the time factor, mentioned earlier, would 
have enabled the culturally diverse teams to overcome differences and be able to deliver the desired outcomes but this study can not make such an argument due to the lack of such data.

$* * * * *$ Insert here Figure $2 * * * * *$

The research invited several senior managers from the company for interviews and three such interviews were arranged with three managers from different cultural backgrounds (A1, A2, A3). The research aim was to get more in-depth view of what happens in multicultural teams and their performance. A number of open ended questions were fielded requiring the respondents to express their view and share their experience in the management of culturally diverse teams. In addition to understanding practitioners view point but also to understand how managers from different cultural background may have differing views on the issue. A1 is a project manager of Indian origin, A2 is a senior manager of Arab origin, and A3 is another senior manager from the USA. A1 felt that from his experience cultural differences do not affect people and that "at work, the professionalism is the basic value or concept that people have, and people at work dump their own old cultural beliefs and start learning from the organisational culture in which they work in". A2, who studied and worked in the USA, disagreed with A1 and explained how the lack of appreciation of cultural differences can lead to serious problems. He tells the story that "there was a western project manager on this project which were located in Dubai, in one of his visits to the site checking the work there he found that most of the people are not there, when he asked about the reason, they told him that they are at their prayer time, as a result he ordered to demolish the mosque which was a temporary one built at site, as a result of this all the people working at this site from all religions, Muslims, Hindus, Singh, and Christians went on strike on the next day. This 
manager didn't understand the importance of religious beliefs for this people, regardless [of what] their religion is, he could solve this problem easily by changing the break time or by other ways that don't hurt these people and what they believe in. " A3 argued that educational background is more important than cultural differences as practices and style of management are more likely to be in line with where individuals were educated is more important than their birth place.

When questioned regarding the impact of culture diversity on project performance again A1 disagreed with this view. A2 on the other hand suggested that such influence will threaten project performance if management is not capable of managing such diversity. A3 saw this issue as a problem if the project manager discriminates between the different members of the project team based on their nationality. A1 argued that enabling and promoting team work would eliminate any possible misunderstanding between project team members, "people, in organisations, try always to create groups or join ones in which they believe that they would be more comfortable and confident, these groups are not necessary formed based on people's nationalities or cultures, but may have different reasons. The management role is to eliminate these groups and concentrate on getting people in a team work." A2 preferred to create a system of strong rules and regulations, and to have a strong organisational culture which can overcome the cultural differences between individuals. Moreover, he suggested having multiple internal programmes and activities that enhance individuals' behaviour and break out cultural barriers between them. A3 agreed that to avoid informal cultural groups from forming within the organisation it is necessary to have strong organisational culture and strong rules, and also to have an open door policy for the top managers. If informal 
organisations or groups phenomenon is not solved immediately, it can take over the system and be the decision maker in the organisation.

\section{CONCLUSION}

The establishment of CIB working commission, W112, for Culture in Construction is an indication of the increased interest in how to manage cultural differences to the benefit of project stakeholders. This research focused on understanding the impact of cultural diversity on project team performance. The data collected an analysis did not look into the possibility how cultural diversity may have had a different impact on different professionals as has been argued by Mahalingam and Levitt (2007).

The research quantitative data did not provide the strong lead that was expected to explain the nature of the relationship between cultural diversity and project team performance. Although not significant the relationship between diversity and overall evaluation of team performance was negative. One of the performance criteria that have shown to be significantly influenced by cultural diversity was output, productivity, and efficiency. This result provides an indication of the negative influence of diversity on project team performance.

It is interesting to note that the project managers, who were shown to be employee oriented, rating of their teams' performance behaviour, as described by Mathieu et al (2008), were not affected by changes their diversity index. However, the performance criteria that have 
suffered on the increase of cultural diversity can be argued to require closer relationships and integrated working practices among culturally diversified teams. The lack of data on the time such teams have spent together has disadvantaged the research by not enabling it to gauge the affect of this important factor on the results. The people/relation oriented management would be expected to have dealt with many of the performance behaviour dimensions but yet to deliver on outcomes. The expectation is that over time such behaviours should be able to deliver the outcomes. However, in the case of this company there is a danger that the overall performance measure where output is one of many criteria may create the false impression that such teams are performing well when the output of the team is undermined by the lack of effective diversity management.

\section{REFERENCES}

Abbassi, S.M. and Hollman, K.W. (1991), Managing cultural diversity: the challenges of the 90s , ARMA Records Management Quarterly, Vol. 25 No. 3, pp. 24-32.

ADCCI (2007a) Abu Dhabi Economic Performance and Outlook, Information Centre, AD, UAE.

Adler, N. J. (1991) International Dimension of Organizational Behaviour, PWS-Kent Publishing Company, Boston., MA.

Adler, N. J. (2002) International Dimensions of Organisational Behaviour, 4th edition, SouthWestern.

Adler, N.J and Gunderson, A (2008), International Dimensions of Organizational Behavior, $5^{\text {th }}$ edition, Thompson.

Appelbaum, S H and Shapiro, B (1998) The management of multicultural group conflict, Team Performance Management, 4(5), pp. 211-234. 
Blau, P. M. (1977) Inequality and Heterogeneity, New York: Free Press.

Cox, T. H. (1993) Cultural Diversity in Organisations: Theory, Research and Practice. Berrett-Koehler: San Francisco, CA.

Cox, T. H. (1991) Managing Cultural Diversity Implications for Organizational Competiveness, Academy of Management Executives, 5(3), pp. 45-56.

Daft, R.L. (2003) Management, 6th ed., Thomson Learning, London.

DCCI (2007) The Economic Bulletin, June, Dubai, UAE.

Dulaimi, M. F. and Langford, D. (1999) Job behavior of construction project managers: Determinants and assessment, Journal of Construction Engineering and Management, Vol. 125, No. 4, pp. 256-264.

Dulaimi, M. (2008) Who Moved the Melting Pot, Construction Week, 02 February 2008.

Fellows, R., and Liu, A. (2006) Culture as a category of risk in construction, Joint International Conference on Construction Culture, Innovation, and Management (CCIM), 26-29 Nov. 2006, pp. 138-147, The British University in Dubai, Dubai, UAE.

Fleury, M.T.L. (1999) The management of culture diversity: lessons from Brazilian companies, Industrial Management and Data Systems, Vol. 99 No. 3, pp. 109-14.

Fiedler, F.E. and Garcia, J.E. (1987) New Approaches to Leadership, Cognitive Resources and Organizational Performance, New York: John Wiley and Sons.

Francesco, A. and Gold, B. (2005) International Organisational Behaviour, $2^{\text {nd }}$ ed., New Jersey, Prentice Hill.

Gregersen, H., Morrison, A., and Black, J. (1998) Developing Leaders for the Global Frontier, Sloan Management Review, Fall, pp. 21-32. 
Hambrick, D.C. (1994) Top management groups: A conceptual integration and reconsideration of the 'team' label', In Shaw, B.M. and Cummings, L.L. (Eds), Research in Organizational Behavior, JAI Press, Greenwich, CT, pp. 171-213.

Hampden-Turner, C. and Trompennars, A (1993) The seven Cultures of Capitalism, Garden City, NY: Doubleday.

Hill, C.W. (1997) International Business: Competing in the Global Market Place, Chicago: Irwin.

Hofstede, G. (1980), Culture's Consequences: International Differences in Work-related Values, Sage Publications, Beverly Hills, CA

Hofstede, G. (1997) Cultures and Organizations: software of the mind, McGraw-Hill, New York.

Iles, P. (1995) Learning to Work with Difference, Personal Review, 24(6), pp. 44-60.

Jehn, K A (1995) A Multi-method examination of the benefits and determinants of intragroup conflict, Administrative Science Quarterly, 40 (2), pp. 256-282.

Jokinen, T. (2005) Global Leadership Competencies: A Review and Discussion, Journal of European Industrial Training, 29(3), pp. 199-216.

Karoc-Kakabadse, N. and Kouzmin, A. (2001), Low- and high-context communication patterns: towards mapping cross-cultural encounters, Cross Cultural Management, Vol. 8 No. 2, pp. 3-24.

Kokt, D. (2003) The impact of cultural diversity on work team performance: A South-African perspective, Team Performance Management: An International Journal, 9 (3/4), pp. 78 83.

Laurent, A (1983) Cultural diversity of western conceptions of management, International Studies of Management and Organisations, Vol XIII No. 1-2, pp. 75-96 
Loosemore, M., Phua, F., Dunn, K. and Ozguc, U (2010) Operatives' experiences of cultural diversity on Australian construction sites, Construction Management and Economics, 28, February, pp. 177-188, Routledge.

Luthans, F. (2005) Organizational Behavior, $10^{\text {th }}$ Edition, Boston, McGraw Hill.

Mahalingam, A. and Levitt, R. E. (2007) Institutional Theory as a Frameowrk for Analyzing Conflicts on Global Projects, Journal of Construction Engineering and Management, ASCE, 133 (07), pp. 517-528.

Mathieu, J., Maynard, M T, Rapp, T, Gilson, L (2008) Team Effectiveness 1997-2007: A Review of Recent Advancements and a Glimpse into the Future, Journal of Management, Vol. 34 No. 3, June 2008 410-476, Sage.

Matveev, A. and Milter, R. (2004) The Value of Intercultural Competence for Performance of Multicultural Teams, Team Performance Management, 10(5/6), pp. 104-111.

McCuiston, V., Wooldridge, R. and Pierce, C. (2004) Leading the Diverse Workforce, The Leadership and Organisational Development Journal, 25 (1), pp. 73-92.

Miller, G. E. and Rowney, J I A (1999) Work Diversity Management in a Multicultural society, Women in Management Review, 14(8), pp. 307-315, MCB University Press.

Milliken, F. and Martins, L. (1996) Searching for Common Threads: Understanding the multiple effects of diversity in Organizational groups, The academy of Management Review, 21 (4/5), pp. 402-433.

Miroshnik, V (2002) Culture and International Management: a review, Journal of Management Development, 21 (7), pp. 521-544, Emerald.

OBG (Oxford Business Group) (2007a) The Report: Abu Dhabi 2007, UAE.

OBG (Oxford Business Group) (2007b) The Market: Real Estate 2007, Dubai, UAE. 
Proehl, R. (1996) Groups in the Workplace 2000, Cross Cultural Management: An International Journal, 3(1), pp. 37-44.

Richard, O. C., Murthi, B. P., and Ismail, I. (2007) The impact of racial diversity on intermediate and long-term performance: The moderating role of environmental context, Strategic Management Journal, 28 (12), pp. 1213-1233.

Robbins, S. (2005) Organisational Behaviour: Concepts, Controversies and Applications. $11^{\text {th }}$ ed. New Jersey: Prentice Hall

Sirmon, D G, and Lane, P J (2004) A model of cultural differences and international alliance performance, Journal of international Business Studies, 35 (4), ppp. 306-319, Palgrave Macmillan

Seymen, O (2006) The cultural diversity phenomenon in organisations and different approaches for effective cultural diversity management in organisations and different approaches for effective cultural diversity management: a literary review, Cross Cultural Management: An International Journal, 13 (4), pp. 296-315.

Shenkar, O, and Zeira, Y. (1992) Role Conflict and Role Ambiguity of Chief Executive Officers in International Joint Venture, Journal of International Business Studies, 23(1), pp. 55-75.

Shenkar, O. (2001), “Cultural distance revisited: towards a more rigorous conceptualization and measurement of cultural differences', Journal of International Business Studies, Vol. 32 No. 3, pp.519-535.

Triandis, H.C., Hall, E.R., Ewen, R.B. (1965), "Some cognitive factors affecting group creativity", Human Relations, Vol. 18 No.1, pp.33-5

Vecchio, R.P., and Appelbaum, S.H. (1995). Managing Organizational Behavior: A Canadian Perspective, Dryden-Harcourt Brace and Co., Toronto, Canada, 696 pp. 
Watson, W. E., Kumar, K., and Michaelsen, L. K. (1993) Cultural diversity's impact on interaction process and performance: Comparing homogeneous and diverse task groups. Academy of Management Journal, 36 (3), 590-602.

Williams, K.Y., and O'Reilly, C.A. (1998) Demography and diversity in organisations: A review of 40 years of research, Research in Organizational Behaviour, 20 (20), pp. 77-140. Wright, P.M., Noe, R.A. (1996) Management of Organizations, Richard Irwin, Chicago, IL. Chuang, You-Ta, Church, C. and Zikic, J (2004) Organisational Culture, Group Diversity, and Intra-Group Conflict, Team Performance Management, 10 (1/2), pp. 26-34. 